\title{
Degradation of Reactive Black 5 and Basic Yellow 28 on Metallic-Polymer Composites
}

\author{
M.A. Méndez, ${ }^{a}$ G.R. Tovar, ${ }^{a}$ M.M. Dávila, ${ }^{a,}{ }^{*}$ O. Ornelas, ${ }^{b}$ M.P. Elizalde ${ }^{b}$

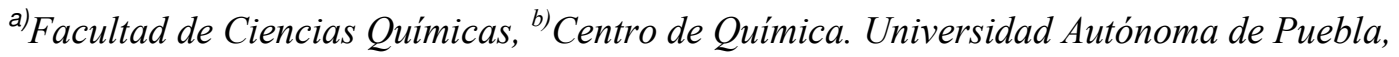 \\ Apdo. Postal J-55. 72571 Puebla, México
}

Received $1^{\text {st }}$ July 2007; accepted $21^{\text {st }}$ November 2007

\begin{abstract}
The textile dyes Reactive Black (RB5) and Basic Yellow 28 (BY28) were individually exposed to electrochemical treatment in $0.1 \mathrm{M} \mathrm{KOH}$ and in phosphate buffer solution $\mathrm{pH}$ 5.1, respectively. The cathodic decolorization of the azo dye RB5 was carried out using a Ni-polyvinylchloride composite. The methine dye BY28 was anodically treated on a Co-polyvinylchloride. The electrochemical study of the dye solution was carried out by repetitive cyclic voltammetry (RCV) under potentiostatic conditions in stationary and flow regime. The effect of various experimental parameters, such as potential and electrolysis time was investigated. The studies showed that for the RB5 (20 to $80 \mathrm{ppm}$ ) dye solutions, around $98 \%$ of the color was removed after 60 min treatment at $-3.0 \mathrm{~V}$ vs. SCE. It was also demonstrated that for the BY28 (15 ppm) dye solution, 6-10 cycles or low potentials $(-300 \mathrm{mV})$ during 200 min electrolysis were sufficient for the decolorization of the solution. However, COD and TOC values did not decrease.
\end{abstract}

Keywords: electrochemical treatment, degradation, decolorization.

\section{Introduction}

A large variety of synthetic organic dyes is discharged into the effluents during their production and fabrics manufacturing process. At the same time, dye molecules are very visible in wastewaters due to their strong color at very low concentrations and in consequence, the color is one of the most obvious indicators of water pollution. The environmental damage of colored effluents is associated with their toxicity. This has motivated many studies in the last decade toward the development of new processes for the removal of color and organic load from the contaminated effluents. The treatment of colored wastewater is commonly carried out using biological [1-5] and physico-chemical methods [613]. The use of electrochemical techniques for the study and removal of color

\footnotetext{
* Corresponding author. E-mail address: mdavila@siu.buap.mx
} 
and organic load from model colored solutions [13-32] and industrial wastewater has received great attention in the last years [3, 14-31]. Commonly, the electrochemical technology used to remove color utilizes consumable materials with diverse composition, or non-soluble anodes [6-11, 13]. Nevertheless, the performance of non-conventional electrodes as metal-polymer can also be explored. We have reported that the composites metal-polymer can be used as electrodes for electrochemical studies [32-37]. In particular, the dyes Reactive Black 5 and Basic Yellow 28 are among the most commonly used dyestuffs to dye cotton and polyacrylonitrile, and are therefore common industrial pollutants. Our present study provides results describing the electrochemical decolorization of RB5 and BY28 on metal-polymer composites.

\section{Experimental}

\section{Material and reagents}

Reactive Black 5 (RB5) of chemical purity grade (dye content ca. $55 \%$ ) was obtained from Sigma-Aldrich (St. Louis, MO. USA) and Basic Yellow 28 (BY28) was purchased from Orca de Mexico. The molecular structure of each dye is given in Table 1. They were used as received.

Phosphates buffer and $\mathrm{KOH}$ used as the supporting electrolyte were analytical grade reagents from J. T. Baker Chemicals (Phillisburg, NJ, USA). Dyes solutions were prepared with ultra-pure water obtained from a Milli-Q system from Millipore (Joffrey, New Hamshire, USA). Ni and Co powder $(2.2-3.2 \mu \mathrm{m})$ from Alfa Aesar and polyvinylchloride (PVC) from Fluka were used for the preparation of the composites $\mathrm{Ni}-\mathrm{PVC}$ and Co-PVC. An excess of $\mathrm{Ni}$ or $\mathrm{Co}$ metallic powder was dispersed in a solution of PVC, using the necessary and minimum amount of THF to obtain a paste [34, 37].

\section{Electrochemical measurements}

Voltammetric and electrolysis measurements were made with a potentiostat/galvanostat Volta Lab PGZ301. A three- electrode system was utilized, where Ni-PVC, Ni-foil and Co-PVC $\left(1 \mathrm{~cm}^{2}\right)$ were used as working electrodes and a cylindrical $\mathrm{Ni}$ wire mesh $\left(50 \mathrm{~cm}^{2}\right)$ as auxiliary electrode. For the electrochemical measurements of the RB5 and BY28 dye solutions a saturated calomel electrode $(\mathrm{SCE})$ and $\mathrm{Ag} / \mathrm{AgCl}\left(3 \mathrm{~mol} \mathrm{~L}^{-1}\right)$ were used as reference electrodes, respectively. The cathodic decolorization experiments for the RB5 dye solutions were carried out by repetitive cycling potentials in the potential range from 0 to $-3.0 \mathrm{~V}$ at $30 \mathrm{mV} \mathrm{s}^{-1}$ and also in potentiostatic conditions at different cathodic potential values. During these experiments the dye solution was stirred vigorously by a magnetic stirrer. In the case of the BY28 dye solutions, the electrochemical measurements were run in a plug-flow cell, with a Co-PVC electrode as anode. The cell $(50 \mathrm{~mL})$ consisted of a cylindrical, jacketed reaction kettle with one upper and one lower tubulation for pump tubing. A peristaltic pump Spetec Perimax 12 was utilized to produce a continuous circulation at $3 \mathrm{~mL} \mathrm{~min}{ }^{-1}$ into the electrolysis cell. Before the electrochemical studies, the solutions were deareated by passing pure nitrogen gas through it for about 30 min and thereafter, a blanket of nitrogen gas was maintained throughout 
the experiment. During the degradation test, the decolorization extent and dye concentration was followed by spectrophotometry using a Beckman DU 7500 spectrophotometer. Chemical oxygen demand (COD) and total organic carbon (TOC) determinations were carried out by a HACH DR5000 spectrophotometer.

Table 1. Studied textile dyes and name abbreviations used in this study.

Code Structural formulae $\begin{gathered}\begin{array}{c}\text { Commercial } \\ \text { textile name }\end{array} \\ \lambda_{\text {max }} / \mathrm{nm} \\ \text { RB5 }\end{gathered}$

\section{Results and discussion}

\section{Electrochemical decolorization of the azo dye RB5 by cyclic voltammetry}

The electrochemical decolorization of the RB5 dye was studied in $0.1 \mathrm{M} \mathrm{KOH}$ medium by cyclic voltammetry and bulk electrolysis at different cathodic potential values. Fig. 1 shows the potentiodynamic behavior of the Ni-PVC and $\mathrm{Ni}$-foil electrodes in solution containing $20 \mathrm{ppm}$ of the dye RB5 in $0.1 \mathrm{M} \mathrm{KOH}$ at a scan rate of $30 \mathrm{mV} \mathrm{s}^{-1}$ at different cathodic potentials. From Fig. 1a it can be seen that in $0.1 \mathrm{M} \mathrm{KOH}$ the water decomposition on Ni-PVC begins at potentials greater than $-1.0 \mathrm{~V}$ and that in the presence of $20 \mathrm{ppm}$ of the dye RB5 no reductive current appears in the range from 0 to $-1.0 \mathrm{~V}$. However, at the Ni-foil electrode the electrochemical generation of adsorbed hydrogen becomes faster at less cathodic potentials (Fig. 1c). The last is due to the different surface composition, morphology and structure of Ni-PVC and Ni-foil as it has been reported earlier [34].

The voltammograms of a 20 ppm RB5 dye solution recorded with Ni-PVC and Ni-foil at high cathodic potentials are presented in Fig. 1b and 1d. These voltammograms indicate that water decomposition begins at more cathodic potentials, greater than $-1.0 \mathrm{~V}$ on Ni-PVC and that no reductive current peak appears at high cathodic potentials when $20 \mathrm{ppm}$ of the dye RB5 is present. However, after repetitive cycling voltammetry (30 cycles) in the potential range from 0 to $-1.5 \mathrm{~V}$, the decolorization of the RB5 dye solution occurs. These results demonstrated that the dye RB5 could be degradated at Ni electrodes. A more detailed study of the cathodic decolorization of the RB5 solution was carried out by bulk electrolysis in an undivided electrolytic cell. 


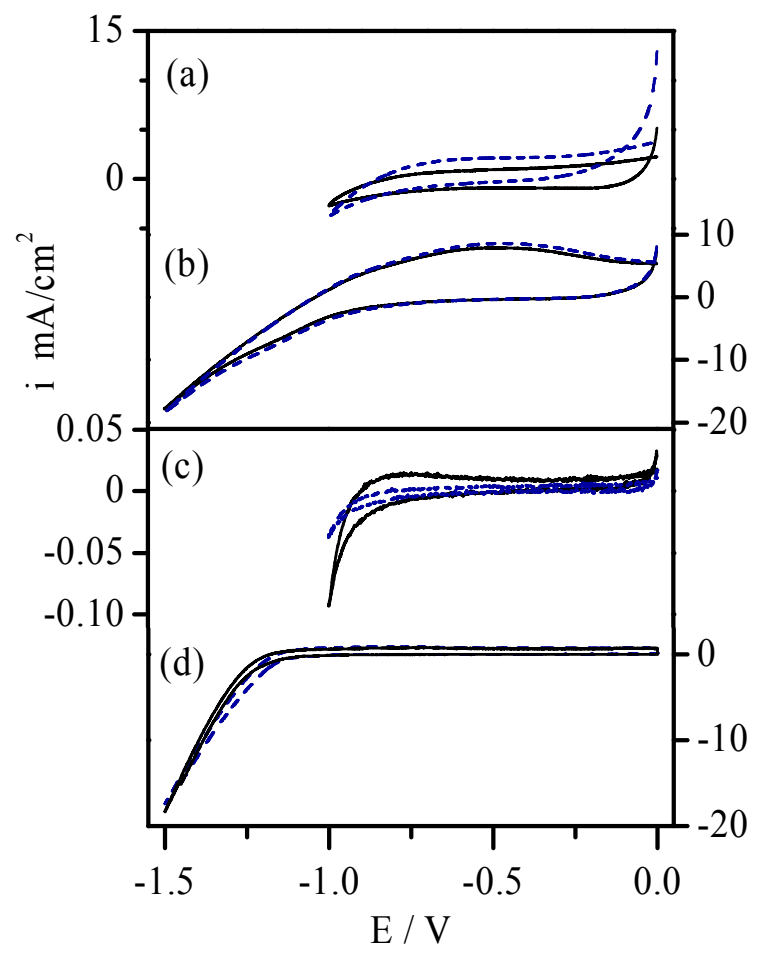

Figure 1. Cyclic Voltammograms of Ni-PVC (a and b) and Ni-Foil (c and d) electrodes in $0.1 \mathrm{M} \mathrm{KOH} \mathrm{(-)} \mathrm{and} \mathrm{in} 20 \mathrm{ppm}$ of RB5 dye solution (---). Scan rate $30 \mathrm{mVs}^{-1}$.

Potentiostatic electrolysis of RB5 dye solution

The potentiostatic decolorization experiments performed with a 80 ppm RB5 dye solution in $0.1 \mathrm{M} \mathrm{KOH}$ at different cathodic potentials showed that the color of the solution gradually diminished with the increase in the cathodic potential. The absorption spectra measured at four different cathodic potentials during $120 \mathrm{~min}$ electrolysis at the Ni-PVC electrode are presented in Fig. 2.

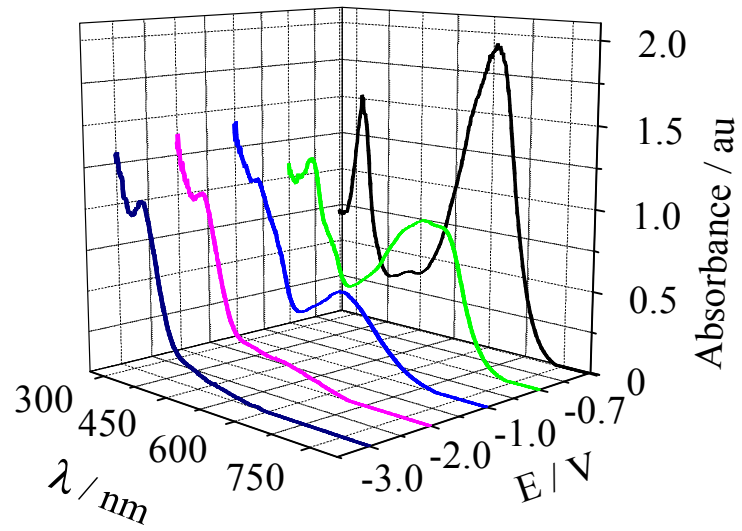

Figure 2. Absorption spectra recorded during the cathodic reduction of RB5 as a function of applied potential. Concentration of the dye: $80 \mathrm{ppm}$. Electrolysis time: 120 $\min$. 
These results showed that the absorbance of the RB5 dye solution at 309 and 600 $\mathrm{nm}$ decreased significantly during the cathodic electrolysis at $-0.7 \mathrm{~V}$. At this potential (near to the potential value at open circuit: $-0.55 \mathrm{~V}$ ) the molecular hydrogen evolution on the Ni-PVC surface was not observed. The color removal efficiency was $54 \%$ (Fig. 3). At a more cathodic potential, for example at $-1.0 \mathrm{~V}$, the absorbance at $600 \mathrm{~nm}$ was suppressed and a new absorption band at $511 \mathrm{~nm}$ appeared (Fig.2). This indicated that new species were formed, which can be attributed to the formation of bis-hydrazo forms, prior to the cleavage of the N-N bond $[15-16,24-25,30]$. At this potential the color removal efficiency was $90 \%$ (Fig. 3) and no generation of hydrogen bubbles was observed on the Ni-PVC surface.

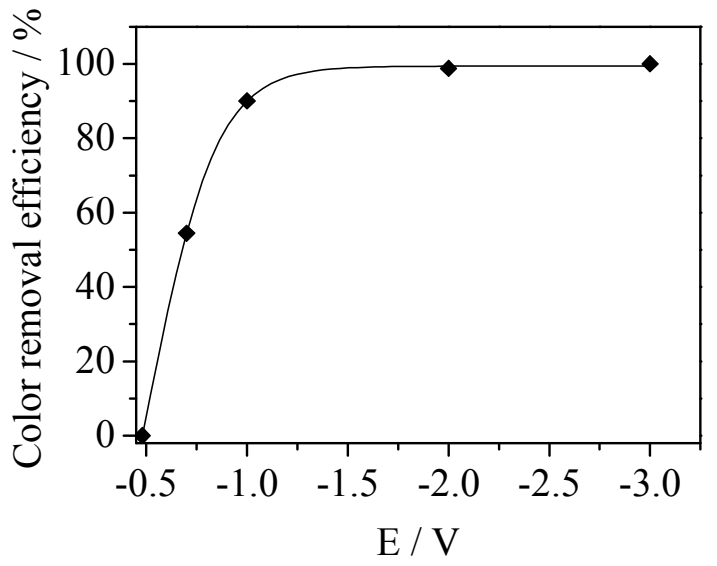

Figure 3. Effect of the applied potential on color removal efficiency of a 80 ppm RB5 dye solution using Ni-PVC as electrode. Electrolysis time: $120 \mathrm{~min}$.

At potentials greater than $-1.5 \mathrm{~V}$, the full cleavage of hydrazo group was accomplished. We confirmed the last by IR spectroscopy and it agrees with the literature reports $[15,18,24]$. During the electrolysis at different cathodic potentials (in the range from -0.7 to $-1.0 \mathrm{~V}$ ) the cathodic current density (i) was lower in presence of $80 \mathrm{ppm}$ of the dye RB5 in comparison with the i obtained without RB5 in the solution. It indicated that on the Ni-PVC surface, the RB5 dye was absorbed and that the decolorization occurred by a direct cathodic electron transfer. The overall reaction scheme for the direct cathodic reduction of azo groups reported in the literature $[15-18,20-21,30-31,46]$ is shown in reactions 1 and 2:

$$
\begin{gathered}
-\mathrm{N}=\mathrm{N}-+2 \mathrm{e}^{-}+2 \mathrm{H}^{+} \leftrightarrows-\mathrm{NH}-\mathrm{NH}- \\
-\mathrm{NH}-\mathrm{NH}-+2 \mathrm{e}^{-}+2 \mathrm{H}^{+} \leftrightarrows-\mathrm{NH}_{2}+\mathrm{H}_{2} \mathrm{~N}-
\end{gathered}
$$

However, it is known that nickel metal is a catalytic metal. For this reason we considered that the Ni-PVC composite material could work both as an electrode (to generate the hydrogen) and as a catalyst in the electrocatalytic hydrogenation (ECH) at high cathodic potentials. Thus, the decolorization of the RB5 dye solution on a Ni-PVC electrode at a high cathodic potential in the concentration 
range from 20 to $80 \mathrm{ppm}$ in $0.1 \mathrm{M} \mathrm{KOH}$ was studied in this context. Fig. 4 shows typical absorption spectra before and after the decolorization reaction of a 20 ppm RB5 solution for different electrolysis times at $-3.0 \mathrm{~V}$ using Ni-PVC as working electrode. From Fig. 4 it can be seen that the absorbance of the peaks at 319 and $600 \mathrm{~nm}$ decreased considerably after $30 \mathrm{~min}$ electrolysis. The rapid disappearance of the $600 \mathrm{~nm}$ absorption band in Fig. 4 suggests that the chromophore responsible for the characteristic color of the RB5 azo dye is breaking down.

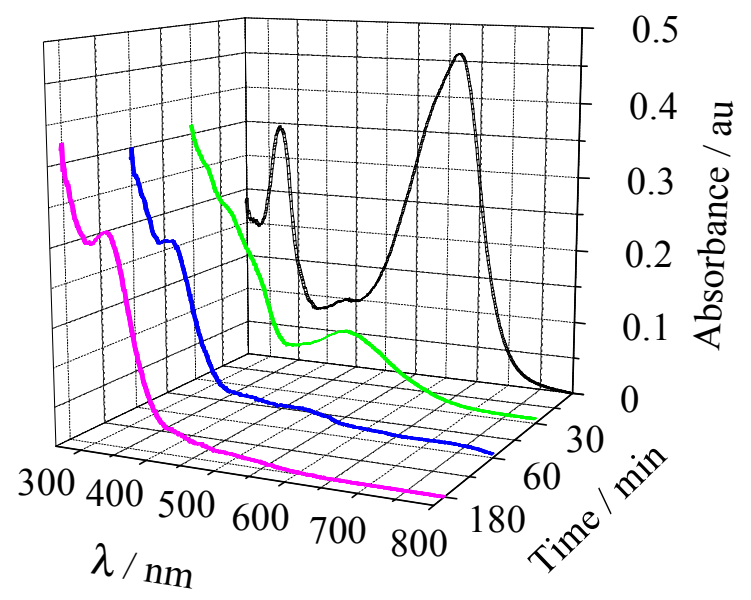

Figure 4. Absorption spectra recorded during the cathodic reduction of RB5 as a function of electrolysis time. Concentration of the dye: $20 \mathrm{ppm}$. Applied potential: $-3 \mathrm{~V}$.

The dependence of the color removal efficiency with electrolysis time (Fig. 5) revealed that the decolorization efficiency increased until $100 \%$ with the increment of the electrolysis time and practically $60 \mathrm{~min}$ were sufficient for full color removal. However, the absorbance values of the band at $319 \mathrm{~nm}$ of the RB5 dye solution did not decrease anymore with electrolysis time. It was a clear indication of the presence of an aromatic compound represented by the naphthalene ring system. In the case of a more concentrated RB5 dye solution (80 $\mathrm{ppm}$ ), the $100 \%$ removal efficiency was obtained after $120 \mathrm{~min}$ electrolysis at the same high cathodic potential of $-3 \mathrm{~V}$. The COD removal was $8 \%$, while the TOC decreased $18 \%$ after $180 \mathrm{~min}$ electrolysis of the $20 \mathrm{ppm}$ RB5 dye solution. It indicates that at high cathodic potentials, only the decolorization of the solution occurred. However, these results showed that the decolorization can be achieved on a Ni-PVC electrode without addition of chemicals, an interesting fact in regard to minimizing chemical consumption in wastewater treatment. Since at high cathodic potentials chemisorbed hydrogen is generated at the Ni-PVC electrode surface by electrolysis of water, we considered the possibility of achieving the decolorization by a cathodic electron transfer according to the reactions 1 and 2 and by ECH. The decolorization achieved by electron transfer and by ECH of azo dyes has already been described [38-47]. 


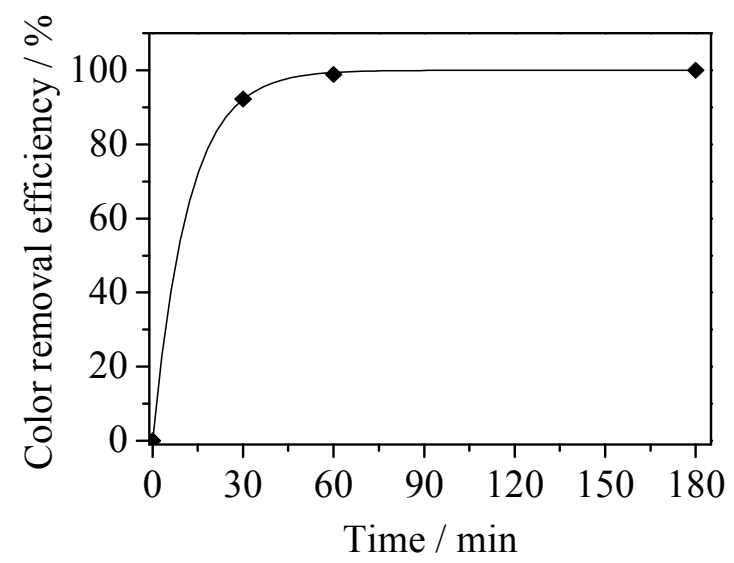

Figure 5. Effect of electrolysis time on color removal efficiency of $20 \mathrm{ppm}$ RB5 dye solution. Applied potential: $-3 \mathrm{~V}$.

In the case of decolorization by $\mathrm{ECH}$, we considered that the active hydrogen species can lead to the rupture of azo-bonds accompanied by an adsorption step $[29,39-41,43,44,47]$.

$$
\begin{aligned}
& \mathrm{H}_{3} \mathrm{O}^{+}\left(\mathrm{H}_{2} \mathrm{O}\right)+\mathrm{e}^{-} \leftrightarrows \mathrm{H}_{\mathrm{ads}}+\mathrm{H}_{2} \mathrm{O}\left(\mathrm{OH}^{-}\right) \\
&-\mathrm{N}=\mathrm{N}-(\text { ads })+2 \mathrm{H}_{\mathrm{ads}} \leftrightarrows-\mathrm{NH}-\mathrm{NH}-(\text { ads }) \\
&-\mathrm{NH}-\mathrm{NH}-(\text { ads }) \leftrightarrows-\mathrm{NH}-\mathrm{NH}-
\end{aligned}
$$

The electrocatalytic hydrogenation involves the electrochemical reduction of water to produce adsorbed hydrogen (reaction 3 ) that chemically reacts with an adsorbed azo compound (reactions 4 and 5) on the low hydrogen overpotential catalyst surface. In our case, the composite Ni-PVC can be considered as a catalyst (with high surface active area), coexisting on the hydrophobic surface (films of polymer PVC) and on hydrophilic sites (nickel oxides). The former may favor the adsorption of the dye and the last, the adsorption of hydrogen. For this reason, we consider that the catalyst Ni-PVC composite served both as an electrode generating hydrogen and as a hydrogenation catalyst (reactions 3-5) according to the following steps (reactions 6-8):

Heyrovsky step

$$
\mathrm{H}_{3} \mathrm{O}^{+}\left(\mathrm{H}_{2} \mathrm{O}\right)+\mathrm{e}^{-}+\mathrm{Ni} \leftrightarrows \mathrm{NiH}_{\mathrm{ads}}+\mathrm{H}_{2} \mathrm{O}
$$

Tafel step

$$
\begin{gathered}
\mathrm{H}_{3} \mathrm{O}^{+}\left(\mathrm{H}_{2} \mathrm{O}\right)+\mathrm{NiH}_{\mathrm{ads}}+\mathrm{e}^{-} \leftrightarrows \mathrm{Ni}+\mathrm{H}_{2}+\mathrm{H}_{2} \mathrm{O} \\
2 \mathrm{NiH}_{\text {ads }} \leftrightarrows 2 \mathrm{Ni}+\mathrm{H}_{2}
\end{gathered}
$$


Electrochemical degradation of the BY28

While the RB5 dye solution was decolorized at cathodic potentials, the BY28 did not exhibit color fate at concentrations greater than $150 \mathrm{ppm}$. For this reason, the BY28 was treated anodically on Ni-PVC and on Co-PVC electrodes. In this paper we only report the results obtained with Co-PVC. The electrochemical oxidation of dye BY28 on a Co-PVC electrode was studied by cyclic voltammetry and under anodic potentiostatic conditions.

Cyclic voltammetric studies showed that the dye BY28 was oxidized on a CoPVC electrode at potentials more anodic than $-0.56 \mathrm{~V}$. The last value corresponds to the potential at open circuit (after $5 \mathrm{~min}$ ) of $15 \mathrm{ppm}$ of the BY28 dye solution in phosphate buffer $\mathrm{pH}$ 5.1. Typical potentiodynamic curves obtained for the 15 ppm BY28 dye in the potential range from -0.5 to $3.0 \mathrm{~V}$ are shown in Fig. 6. Figure 6 (A and $\mathrm{B}$ ) shows that in the first and second cycles the oxidation of the BY28 dye started at $-0.5 \mathrm{~V}$. However, in the subsequent cycles (Fig. 6C) the BY28 dye was oxidized at potentials greater than $1.3 \mathrm{~V}$. This can be due to the gradual accumulation of Co oxides or of the corresponding oxidation products on the electrode surface. Nevertheless, with the repetitive cycling voltammetry, the decolorization of the BY28 dye solution occurred. Fig. 7 shows the typical absorption spectra before and after long time cycling of $15 \mathrm{ppm}$ of the dye BY28. This spectrometric study demonstrated that the degradation process induced a rapid decolorization of the BY28 in the first 6 cycles (Fig.7).

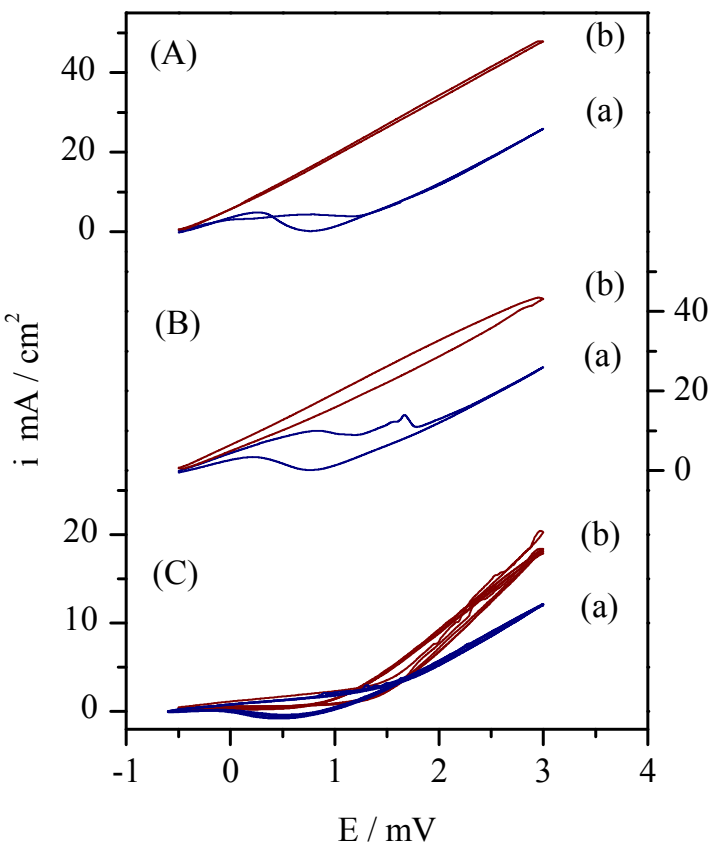

Figure 6. Potentiodynamic profiles obtained on a Co-PVC electrode in phosphate buffer pH 5.1 (a) and in presence of 15 ppm of the dye BY28 (b). (A): 1 cycle, (B): 2 cycles and (C): 6-10 cycles. Sweep rate: $30 \mathrm{mV} \mathrm{s}^{-1}$. E vs. Ag/AgCl.

The color removal efficiency after 6 cycles was $90 \%$, and $97 \%$ after 18 cycles. In agreement with the IR spectroscopy studies, the disappearance of the band at $1330 \mathrm{~cm}^{-1}$ (C-N stretching) indicated the degradation of the dye. However, the 
final COD and TOC conversion decreased mildly, about $10 \%$ and $23 \%$, respectively. In experiments performed in phosphate buffer at $\mathrm{pH} 5.1$ without the dye BY28, the formation of a pink precipitate in the cell and on the electrode surface was observed.

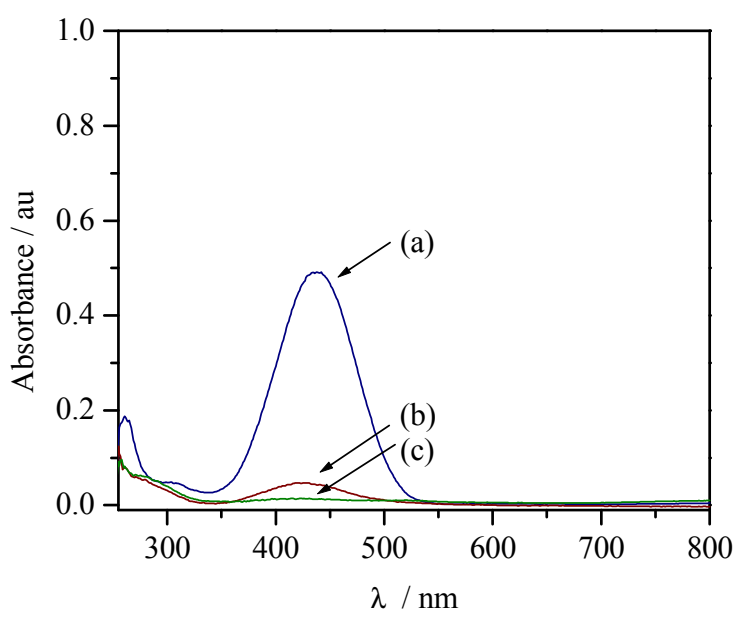

Figure 7. UV-visible spectrum of the 15 ppm BY28 dye solution before RCV (a), after 6 cycles (b) and after 18 cycles (c).

The formation of the precipitate was due to the corrosion of the Co-PVC electrode during the anodic scan in the potential range from -0.5 to $3.0 \mathrm{~V}$. According to the spectroscopy study by diffuse reflectancy, the pink precipitate could be assigned to cobalt phosphate.

With the aim to prevent corrosion and to promote the degradation of the Co-PVC electrode, the study of the decolorization of the BY28 dye solutions was performed at not high anodic potentials (at potentials more anodic that the value of the potential at open circuit: $-0.560 \mathrm{~V}$ ) under potentiostatic conditions in flow regime. The variation of the current density as a function of electrolysis time for 15 ppm of BY28 at different potentials is shown in Fig.8. From this dependence it can be seen that the anodic current density increased when the bulk electrolysis was carried out at more anodic potentials.

The charge associated with the oxidation process and the color removal efficiency for different potentials and electrolysis time is reported in Table 2. These data show that the decolorization of $15 \mathrm{ppm}$ of the BY28 dye solution occurred in the potential range from -0.3 to $1.0 \mathrm{~V}$ and that the color removal depended on the time of the bulk electrolysis. The COD and TOC studies revealed that, under these conditions only the decolorization but not the mineralization was possible. IR spectroscopy studies supporting the identification of degradation products together with the kinetics monitored by HPLC will be reported in another publication. 


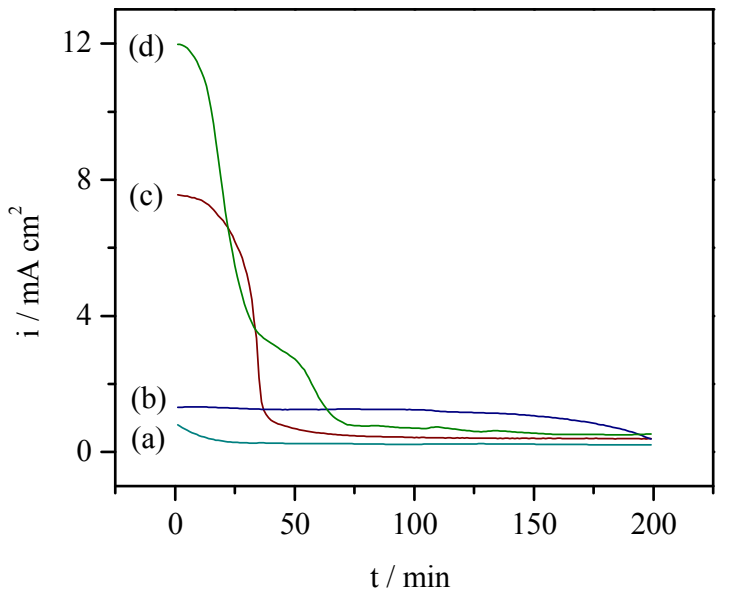

Figure 8. Current-time dependence of phosphate buffer pH 5.1 (a) and of 15 ppm BY28 dye in phosphate buffer $\mathrm{pH} 5.1$ on Co-PVC electrodes at constant potentials of: $-0.3 \mathrm{~V}$ (b), $+0.5 \mathrm{~V}(\mathrm{c}),+1.0 \mathrm{~V}(\mathrm{~d})$.

Table 2. Total charge (Q) and percentage of color removal efficiency (at $\lambda_{\max }=439$ $\mathrm{nm}$ ) for the $15 \mathrm{ppm}$ BY28 dye solution electrolyzed at different constant potentials during 200 and 40 minutes.

\begin{tabular}{cccc}
\hline $\mathrm{t} / \mathrm{min}$ & $\mathrm{E} / \mathrm{mV}$ & $\mathrm{Q} / \mathrm{C} \mathrm{cm}^{-2}$ & Color removal efficiency/\% \\
\hline 200 & -300 & 13.5 & 100 \\
& +500 & 18.0 & 88 \\
& +1000 & 26.5 & 99 \\
40 & -300 & 3.8 & 62 \\
& +500 & 4.2 & 67 \\
& +1000 & 10.2 & 88 \\
\hline
\end{tabular}

\section{Conclusions}

Studies by means of UV-Visible spectroscopy demonstrated that the transformation of the RB5 and BY28 dyes by means of RCVs or across a cathodic and anodic polarization at constant potential on metal-polymer electrodes is possible. For 20 to $80 \mathrm{ppm}$ of RB5, more than $98 \%$ of the color was removed after cathodic treatment at $-3.0 \mathrm{~V}$ during $60 \mathrm{~min}$. The color was totally removed by cathodic reduction in basic medium on a Ni-PVC electrode. Electrocatalytic hydrogenation of RB5 model solutions was achieved by a NiPVC composite electrode. The decolorization increased with a subsequent application of a cathodic potential and increasing the electrolysis time. The composite Co-PVC can be used as electrode for the anodic decolorization of the model BY28 dye solution in phosphate buffer solution $\mathrm{pH} 5.1$. For $15 \mathrm{ppm}$ of the dye BY28, 6-10 cycles or low potentials $(-300) \mathrm{mV}$ and $200 \mathrm{~min}$ electrolysis were sufficient for the decolorization of the solution. The COD and TOC values did not decrease after anodic electroysis of the dyes RB5 and BY28. 


\section{Acknowledgments}

CONACyT for the financial support of the project No. 46377 and the scholarships to Méndez M. A. (No. 144906) and Tovar G. R. (No. 202679).

\section{References}

1. M. Quezada, I. Linares, G. Buitrón, Wat. Sci. Tech. 42 (2000) 329-336.

2. A. Mahdavi, T. Donnelly, G.K. Anderson, Water Res. 35 (2001) 425-432.

3. D.T. Sponza, M. Işik, Enzyme Microb. Technol. 31 (2002) 102-110.

4. G. Gibbs, J.M. Tobin, E. Guibal, Ind. Eng. Chem. Res. 43 (2004) 1-11.

5. C. Carvalho, A. Fernandes, A. Lopes, H. Pinheiro, I. Gonçalves, Chemosphere 67 (2007) 1316-1324.

6. I. Arslan, I.A. Balcioglu, J. Photochem. Photobiol. A: Chem. 141 (2001) 247-254.

7. N.W. Brown, E.P.L. Roberts, A.A. Garforth, R.A.W. Dryfe, Electrochim. Acta 49 (2004) 3269-3281.

8. J. Zhu, J. Zhang, F. Chen, K. Lino, M. Anpo, Top. Catal. 35 (2005) 261268.

9. E. Kusvuran, S. Irmak, H.I. Yavuz, A. Samil, O. Erbatur, J. Hazard. Mater. B119 (2005) 109-116.

10. A. Aguedach, S. Brosillon, J. Morvan, E.K. Lhadi, Appl. Catal. B: Environ. 57 (2005) 55-62.

11. N. Daneshvar, A.R. Khataee, N. Djafarzadeh, J. Hazard. Mater. B137 (2006) 1788-1795.

12. J. Yener, T. Kopac, G. Dogu, T. Dogu, J. Colloid Interf. Sci. 294 (2006) 255-264.

13. S. Rajgopal, T. Karthikeyan, B.G. Prakash Kumar, L.R. Miranda, Chem. Eng. J. 116 (2006) 211-217.

14. M.M. Dávila-Jiménez, M.P. Elizalde-González, A. Gutiérrez-González, A.A. Peláez-Cid, J. Chromatogr. A 889 (2000) 253-259.

15. T. Bechtold, E. Burtscher, A. Turcanu, Textile Res. J. 71 (2001) 870-878.

16. T. Bechtold, C. Mader, J. Mader, J. Appl. Electrochem. 32 (2002) 943-950.

17. M. Cerón-Rivera, M.M. Dávila-Jiménez, M.P. Elizalde-González, Chemosphere 55 (2004) 1-10.

18. A. Sakalis, D. Ansorgova, M. Holčapek, P. Jandera, A. Voulgaropoulos, Int. J. Environ, Anal. Chem. 84 (2004) 875-888.

19. A. Lopes, S. Martins, A. Morão, M. Magrinho, I. Gonçalves, Port. Electrochim. Acta 22 (2004) 279-294.

20. A. Sakalis, K. Mpoulmpasakos, U. Nickel, K. Fytianos, A. Voulgaropoulos, Chem. Eng. J. 111 (2005) 63-70.

21. G. Li, J. Qu, X. Zhang, H. Liu, H. Liu, J. Mol. Catal. A: Chem. 259 (2006) 238-244.

22. E. Chatzisymeon, N.P. Xekoukoulotakis, A. Coz, N. Kalogerakis, D. Mantzavinos, J. Hazard. Mater. 137 (2006) 998-1007.

23. X. Mao, F. Tian, F. Gan, X. Zhang, T. Peng, Fresenius Environ. Bull. 15 (2006) 1-9. 
24. D. Vaněrková, A. Sakalis, M. Holčapek, P. Jandera, A. Voulgaropoulos, Rapid Commun. Mass. Spectrom. 20 (2006) 2807-2815.

25. M.J. Pacheco, M.L.F. Ciríaco, A. Lopes, I.C. Gonçalves, M.R. Nunes, M.I. Pereira, Port. Electrochim. Acta 24 (2006) 273-282.

26. V. López-Grimau, M.C. Gutiérrez, Chemosphere 62 (2006) 106-112.

27. G. Li, J. Qu, X. Zhang, J. Ge, Water Res. 40 (2006) 213-220.

28. A. Sakalis, K. Fytianos, U. Nickel, A. Voulgaropoulos, Chem. Eng. J. 119 (2006) 127-133.

29. E. Brillas, C. Arias, P.L. Cabot, F. Centellas, J.A. Garrido, R.M. Rodríguez, Port. Electrochim. Acta 24 (2006) 159-189.

30. A. Sakalis, D. Vaněrková, M. Holčapek, P. Jandera, A. Voulgaropoulos, Chemosphere 67 (2007) 1940-1948.

31. V.K. Gupta, R. Jain, S. Varshney, J. Colloid Interface Sci. 312 (2007) 292296.

32. M.M. Dávila, M.P. Elizalde, R. Silva, J. Mater. Sci. 32 (1997) 3705-3710.

33. M.P. Elizalde, M. González, E. Garcia, M.M. Dávila, J. Electrochem. Soc. 144 (1997) L263-L266.

34. M. Dávila, M.P. Elizalde, M. González, M.A. Pérez, R. Silva, Electrochim. Acta 44 (1998) 1307-1316.

35. M. González, M.P. Elizalde, L. Baños, G. Poillerat, M.M. Dávila, Electrochim. Acta 45 (1999) 741-750.

36. M.M. Dávila, M.P. Elizalde, M. González, R. Silva, Electrochim. Acta 45 (2000) 4187-4193.

37. M. González, M. Dávila, M.P. Elizalde, A. Manzo-Robledo, N. AlonsoVante, Electrochim. Acta 49 (2004) 3917-3925.

38. Y. Yoshida, S. Ogata, S. Nakamatsu, T. Shimamune, K. Kikawa, H. Inoue, C. Iwakura, Electrochim. Acta 45 (1999) 409-414.

39. H. Ilikti, N. Rekik, M. Thomalla, J. Appl. Electrochem. 32 (2002) 603-609.

40. X.E. Hu, H.W. Yang, X.J. Wang, R.S. Bai, J. Appl. Electrochem. 32 (2002) 321-328.

41. A. Roessler, O. Dossenbach, W. Marte, P. Rys, Dyes Pigm. 54 (2002) 141146.

42. T. Bechtold, A. Turcanu, J. Electrochem. Soc. 149 (2002) D7-D14.

43. P. Dubé, F. Kerdouss, F. Laplante, P. Proulx, L. Brossard, H. Ménard, J. Appl. Electrochem. 33 (2003) 541-547.

44. A. Roessler, O. Dossenbach, P. Rys, J. Electrochem. Soc. 150 (2003) D1D5.

45. G. St-Pierre, A. Chagnes, N.A. Bouchard, P.D. Harvey, L. Brossard, H. Ménard, Langmuir 20 (2004) 6365-6373.

46. T. Bechtold, A. Turcanu, J. Appl. Electrochem. 34 (2004) 903-910.

47. C.M. Cirtiu, H.O. Hassani, N.A. Bouchard, P.A. Rowntree, H. Ménard, Langmuir 22 (2006) 6414-6421. 